Pure Sciences

Poster

Abstract ID: 129

\title{
Extraction of omega 3 fatty acids from sardine byproducts using supercritical carbon dioxide $\left(\mathrm{SC}-\mathrm{CO}_{2}\right)$
}

\author{
Sahena F. ${ }^{a}$ | Zaidul I.S.M. ${ }^{b} \mid$ Kamaruzzaman B.Y ${ }^{a} \mid$ Abir H.M. ${ }^{c} \mid$ Rukshana A.H. ${ }^{d}$ \\ ${ }^{a}$ Kulliyyah of Science, International Islamic University Malaysia \\ ${ }^{b}$ Kulliyyah of Pharmacy, International Islamic University Malaysia \\ 'Faculty of Agricultural Engineering \& Technology, Bangladesh Agricultural University, \\ Mymensingh, Bangladesh. \\ ${ }^{d}$ Faculty of Basic Medical and Pharmaceutical Sciences, University of Science and Technology \\ Chittagong (USTC), Chittagong, Bangladesh.
}

Introduction: Sardine generally processed as canned fish, and in consequence of a lot of solid waste are generated as byproducts which could be good sources of fish oil. Omega-3 fatty acid compositions of total lipids extracted by supercritical carbon dioxide $\left(\mathrm{SC}-\mathrm{CO}_{2}\right)$ from sardine fish by-product (head, skin and viscera) were determined and the results were compared with Soxhlet extraction. Methods: $\mathrm{SC}-\mathrm{CO}_{2}$ extraction was performed at the optimized condition at a temperature of $60{ }^{\circ} \mathrm{C}$, the pressure of $35 \mathrm{Mpa}$ and flow rate of 3 $\mathrm{ml} \mathrm{min}{ }^{-1}$. Results: Highest yield was obtained from the skin $(42.5 \%)$ followed by the head $(22.4 \%)$ and the viscera $(9.6 \%)$ which is closer to that of the yield of Soxhlet extraction method where 44\%, $23 \%$ and $11 \%$ (on dry basis) oil were yielded from skin, head and viscera, respectively. Saturated fatty acid was dominant incorporate with monounsaturated and polyunsaturated fatty acid in all organs and the difference of extracted fatty acids between $\mathrm{SC}-\mathrm{CO}_{2}$ and Soxhlet methods were insignificant. Docosahexaenoic acid (DHA) was characteristically major PUFA accounting $19.8 \%$ in head, $15.4 \%$ in skin and $13.6 \%$ in viscera of the total fatty acids. Conclusions: Total oil extracted by $\mathrm{SC}-\mathrm{CO}_{2}$ had lower free fatty acid content than the oil extracted by Soxhlet method. Thus, $\mathrm{SC}-\mathrm{CO}_{2}$ could be the effective method for extracting omega-3 PUFA rich fish oil from sardine by-products.

KEYWORDS: Sardine byproducts, Omega 3 fish oil, Supercritical carbon dioxide, Soxhlet extraction 